\title{
Las cárceles españolas de la llustración y su censura en la Academia (1777-1808)
}

\author{
José Enrique García Melero
}

"Las cárceles todos las conocen"

(Comentario en nota de Ortiz y Sanz a su edición de Vitruvio de 1787, pág. 112)

Humanizar las cárceles construyéndolas de nueva planta según princjpios de utilidad, sencillez, economía y decoro, era, al parecer, uno de los objetivos principales de la Arquitectura de la llustración europea sobre esta tipología. Montesquieu, Rousseau, Beccaria, Burton, Howard, Bentham, Lardizábal y otros muchos se ocuparon de ella desde una perspectiva múltiple jurídica, ética-filosófica, pedagógica y también arquitectónica. La llustración establecería varias de las principales bases ideológicas de la ciencia penitenciaria moderna.

Si^ lugar se hallaba la mayoría de las veces en las ciudades y villas españolas en o junto a las Casas Consistoriales, formando un conjunto arquitectónico de gran coherencia dentro de la ciudad. A él se unían en bastantes ocasiones diversos habitáculos para otras distintas funciones pragmáticas. Se trataba de mejorar la calidad de vida física y hasta cultural de la población. Posada, escribanía, archivo, escuela e incluso mesón, carnicería, panadería, granero y pontones se encontraban en un mismo espacio arquitectónico o relacionándose estrechamente entre sí. Se formaba, de este modo, en torno al ayuntamiento, en la plaza mayor, y a la aneja cárcel, pequeños "centros cívicos" polifuncionales, que procuraban, por una parte, el sustento del cuerpo y, por la otra, el gobierno de la villa y hasta la formación del espiritu; pero también la represión del delito como castigo y, del mismo modo sobre todo desde entonces, en calidad de reeducación.

Vitruvio, la principal referencia arquitectónica clásica de autoridad en la España de la llustración, pareció olvidarse de la cárcel en su tratado de arquitectura, edificio al que no concedió una categoria de primer orden similar al templo, al palacio, al hospital, o al teatro, por ejemplo. Tan sólo la menciona de pasada, y así se refleja en la edición de Ortiz y Sanz de 
1787, quien en nota, quizá un tanto irónicamente, comentó: “las cárceles todos las conocen" ". Vitruvio hizo una simple referencia sobre esta tipologia, al indicar que junto al erario o tesoro de la ciudad y la curia, lugar de gobierno, debía situarse al lado del foro de la urbe, "sin que su magnitud y simetría desdigan de la de aquel». Pero el arquitecto romano no indicó ni como se debía construir ni cuál sería su aspecto en ningún caso. No resulta extraña, por lo tanto, su ubicación en la ciudad del Antiguo Régimen muchas veces en la plaza principal de las villas españolas, formando un conjunto arquitectónico con otras obras de carácter público relacionadas con el ejercicio del poder, sistema urbanístico bien representativo, históricamente ya tradicional.

Quizás la falta de referencia vitruviana a este edificio se debiera a la tendencia clasicista a silenciar, y hasta a ocultar, los lugares indicadores de la limitación vital y de la miseria del hombre. Pero, además, la cárcel tan sólo era un habitáculo de residencia "obligada», de "mal estar», similar exteriormente a la vivienda y, algunas pocas veces, hasta al palacio, o al convento, o tal vez con más exactitud, a la ciudadela, aunque siempre represivo, por lo que era susceptible de aportar una apariencia exterior fortificada en cierta forma tan noble como estas tipologías, mas con un interior la mayoría de las veces bastante miserable. Algunos conventos habian sido readaptados en España para que sirvieran de cárceles, y las celdas de los monjes, lugar de retiro y sueño, de reflexión y hasta de oración privada, se convirtieron en celdas para los presidiarios, que debian pensar sobre el delito cometido y su castigo, y arrepentirse.

Por tales motivos tampoco resulta extraño, asi pues, que la cárcel no fuera tema usual para las oposiciones a los premios de arquitectura de la Academia. El “olvido» de Vitruvio y su condición de edificio para la represión, hacian más preferible durante la época ilustrada en los medios académicos la elección de otros asuntos para competir bastante más nobles. La cárcel quedaría aqui "encerrada" también dentro del conjunto palacial de las Casas Consistoriales, herederas de la antigua condición de curia de la ciudad, cuyo sistema arquitectónico había sido tan cultivado durante la época del barroco. No obstante, en 1754 un Juan de Villanueva de quince años obtuvo el primer premio de tercera clase en la prueba de pensado de la Academia por su fachada de la Cárcel de Corte, desmenuzando en otros cinco dibujos los distintos elementos ar-

VItRuvio Polion: "Los diez libros de arquitectura". Traducidos del latín, y comentados por Don Joseph Ortiz y Sanz, Presbitero. En Madrid, en la Imprenta Real, año de 1787. Sobre el erario, cárceles y curia libro $V$, cap. II, pág. 112 
quitectónicos, que configuran la portada. Después tan sólo se la menciona como asunto de tales premios en 1802 en calidad de tema para el de primera clase; pero en esta ocasión es una dependencia más del edificio con destino a Ayuntamiento para la Corte, luego de aludirse a las Salas, que debían tener para las juntas públicas y particulares, un Salón para festejos reales y todas las oficinas correspondientes a su destino. Machuca Mantrana resultó premiado.

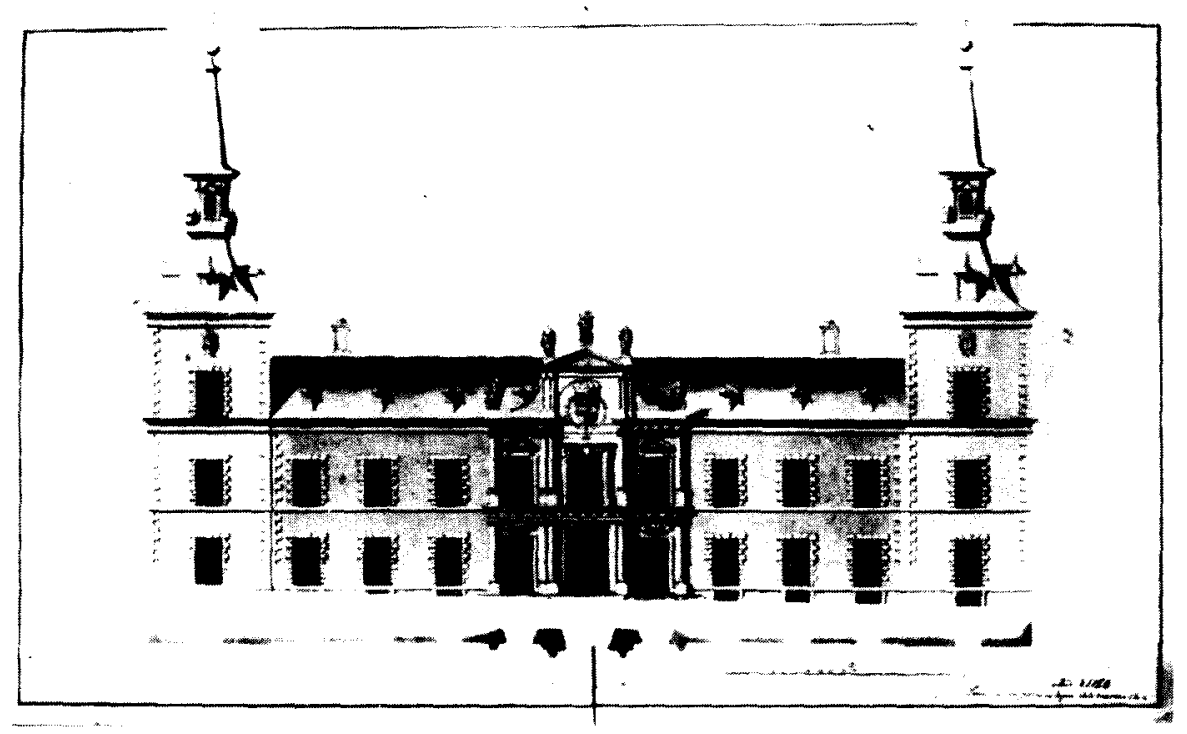

Lám. 1. Juan de Villanueva “Cárcel de Corte», 1754. Primer premio de $3^{a}$ clase. Prueba de pensado.

No obstante, al despuntar el llamado romanticismo histórico español la cárcel se constituye en tema frecuente de debate académico. Así sucede con motivo de las disertaciones de contenido teórico que los arquitectos debian presentar a la Academia para acceder al grado de académicos de mérito e incluso también como tema más técnico que teórico para el examen de los aspirantes al título de arquitectn. Desde 1806, confirmándose en $1820^{2}$, la tipología carcelaria se introduce en los libros de asuntos para estos exámenes que se debian sortear, eligiendo el aspirante entre una terna. $Y$ algunos examinandos lo prefirieron a otros más no-

Hay un cuaderno de pruebas y exámenes a que debian sujetarse los aspirantes al titulo de Académicos de mérito por la Pintura, Escultura, Arquitectura y ambos grabados de 1820-21 en A.A.S.F.: leg.: $17-3 / 1$ 
bles, y menos represivos y tristes. El enunciado del tema para la obtención del grado de académico era: «Determinar qué circunstancias y clases de distribución deben darse a la cárcel pública capaz de contener de 300 a 400 presos; y cómo se hará compatible la seguridad de éstos con la luz y ventilación de las piezas aún para mayores reos". Sobre este asunto disertaron Francisco Barra en $1832{ }^{3}$ y Manuel Cabrera Pérez en $1842^{4}$.

Barra ya en 1832 estableció en su disertación una serie de circunstancias que el arquitecto debería tener presentes al proyectar una cárcel. Estableció entre ellas una jerarquía que iba desde la seguridad completa hasta la clasificación de los presos y su separación por departamentos, fácil inspección, continua ocupación en el trabajo e instrucción religiosa, disposición para que se ventilasen al aire libre, incomunicación de algunos de ellos de todas clases y estancia solitaria de noche. En su análisis consideró fuentes inglesas, tanto a Burton, Howard y Cunningham, de quien tradujo en el discurso su instrucción para la construcción de una cárcel, como a Bentham, cuyo panóptico cuestionó al preferir el sistema de pabellones separados formando una figura circular.

Pero la cárcel también sería objeto de prueba de pensado en la Academia madrileña para los aspirantes al título de arquitectos. Así, entre los años 1822 y 1845 el tema carcelario fue elegido entre una terna de asuntos por once aspirantes de los 276 examinados durante este periodo. Ahora la cárcel admite variaciones en los enunciados: desde una cárcel pública, de la Corona, correccional y de detención a una casa consistorial y cárcel, y, asimismo, audiencia con cárcel. Es de destacar aquí que ya en 1831 se propuso a José Solano como asunto una casa de corrección en forma panóptica en alusión clara al modelo de Bentham. Los arquitectos que se examinaron sobre esta tipologia en la Real Academia de San Fernando fueron: el zamorano Bartolomé Tejada Díez (1820), el bilbaíno Salustiano Ardanaz (1826), Juan Ibáñez de la ciudad de Cartagena (1826) ${ }^{5}$, el madrileño José $M^{a}$ de Mariategui (1830), el burgalés Marcos Arnaiz (1830) ${ }^{6}$, el mencionado

La terna de temas, que salió en suerte a Francisco BARRA, se sorteó en la junta ordinaria del 12 de agosto de 1832. La disertación está fechada el 22 de diciembre de ese mismo año. A.A.S.F.: leg.: 313-2/3.

La disertación de CABRERA de 1842 en A.A.S.F.: 308/44-3.

"Ayuntamiento, peso real y cárcel", por BARTOLOME TEJADA DIAZ. 1820. A.A.S.F.: 68-6/4."Ayuntamiento y cárcel", por SaLuStIANO ARDANAZ. 1826. Ibidem.: 68-7/4.— "Cárcel pliblica", por JUAN IBÁÑEZ. 1827. A.A.S.F.: 8-2/2.

"Cárcel correccional", por Jose M" DE Mariategul. 1830. Ibidem.: 9-4/2.— "Casa consistorial y cárcel", por Marcos Arnalz. 1830. Ibidem, 9-4/2. 
madrileño José Solano (1831) ' . el también madrileño Manuel Mostaza $(1833)^{\circ}$, el zaragozano Juan Jimeno y Casanova (1833) ${ }^{9}$, Miguel Geliner y Gelma de Igualada (1838) ${ }^{10}$, el donostiarra Joaquín Ramón de Echeveste (1839) " y el sevillano Manuel de Zayas y Algarrán (1845) ${ }^{12}$.

\section{LA CÁRCEL EN LA TRATADÍSTICA ARQUITECTÓNICA ACADÉMICA}

No obstante al silencio de Vitruvio, Alberti en su "Architettura", publicada por vez primera en Florencia en 1550, hizo referencia al edificio de la cárcel en el capítulo xill del Libro $v$, dedicado a las obras de uso restringido ${ }^{13}$. Preocupado siempre por la urbe, la situó en una zona protegida y nada solitaria de la ciudad para evitar las fugas. Distinguió dos partes distintas en ella: el recinto elevado y amurallado con torres y paseos de circunvalación, y el edificio de reclusión con fuertes muros. Su interior debia tener diferentes zonas, constituidas por un vestíbulo, un "patio nada triste», al parecer cubierto, en donde recibirían enseñanzas los reclusos, que lo desearan, y otro descubierto porticado. Diferenció tres tipos de ellas según la clase distinta de delito cometido más o menos grave por el recluso, instalando a los criminales peores en las dependencias más recónditas. La cárcel de Alberti está, asi pues, jurídica y espacialmente jerarquizada. Era lugar de aislamiento y de castigo; pero la reeducación humanistica de los presos tenía cabida en ella.

Alberti fue uno de los tratadistas más considerados en el medio académico. En la biblioteca de la Academia de San Fernando estaba la edición florentina de $1550^{14}$, así como la traducción del latín en romance del

"Casa de Corrección en forma panóptica", por José SOLANo, Marqués de Socorro. 1831. lbidem, $9-6 / 2$ bis.

"Una cárcel de Corona", por Manuel Mostaza. 1833. Ibidem, 10-2/2.

"Una cárcel o casa de detención", por Juan Jimeno y Casanova. 1833. Ibidem, 10-2/2.

"Una Carcel y Presidio Correccional", por Miguel Gelinef y Gelma. 1838. Ibidem, 10-3/2 bis.

"Una Cárcel", por Joaquin Ramón de Echeveste. 1839. Ibidem, 11-1/2.

"Audiencia con cárcel", por Manuel de Zayas y AlgarRan. 1845. Ibidem, 12-4/2.

ALBERTI, LEON BATISTA: "L'Architettura" di... Tradotta in lingua Fiorentina da Cosimo Bartoli Gentilhuomo \& Academico Fiorentino. Con la aggiunta de Disegni. In Ferenze. Appresso Lorenzo Torrentirı Impressor Ducale, MDL. Véase la edición de Madrid, Akal, 1991, "De Re Aedificatoria" de

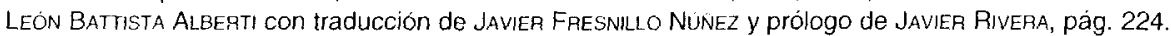

14 B.A.S.F.. B-1619. Para conocer los libros existentes en la Academia de la llustración es importante la consulta del "Indice de los libros existentes en la biblioteca de la Real Academia de San Fernando". Lo realizó el primer bibliotecario de la Academia, Juan Pascual y Colomer, hacia 1794 o 1795. Fue añadido posteriormente en 1826 por su sucesor José Franco con 210 papeletas de obras adquiridas después. A.A.S.F.: 71/3. 
alarife madrileño Francisco Lozano, bastante confusa en su redacción, impresa en Madrid en 1565, el mismo año que apareció el Vitruvio de Urrea y Gracián ${ }^{15}$. Pero también se hallan en tal librería la de Monte Regale de $1565^{16}$ y la reedición romana de la de Cosimo Bertoli por Giovanni Zempel de 1784, que bien podría haber servido a la Comisión de Arquitectura ${ }^{17}$.

Como es sabido, la edición príncipe de Alberti, quien elaboró toda una teoría arquitectónica al modo vitruviano, " $D e$ re aedificatoria», habia sido publicada en latín, el idioma culto, y sin estampas en Florencia por Nicolo di Lorenzo Alemanno en 1485. La falta de ilustraciones se suplió con la traducción al italiano del humanista Cosimo Bartoli (1503-1572), quien las añadió. Por este motivo, parece lógico que la Academia madrileña poseyera esta edición de 1550 y su reedición de 1784, pues necesitaba de un repertorio de láminas, to cual hacia al tratado mucho más operativo y didáctico.

Sin embargo, a finales del siglo de la llustración, en 1797, el mismo año que Ortiz y Sanz publicaba en la Imprenta Real su traducción de Palladio, apareció la segunda edición española en tres tomos. Así, en las postrimerías del xVIII se disponía ya en España de reediciones importantes de los principales textos del clasicismo, vieja aspiración académica, tanto de Vitruvio como de Viñola, Palladio y Alberti.

Benito Bails trató sobre este edificio en su "Arquitectura civil", que formaba parte como tomo Ix, parte I, de los "Elementos de Matemáticas", aparecido primero en 1783 y, después, ya su segunda edición en $1796^{\text {is }}$. Resulta curioso que analizara tal tipología entre las pocas, pero importantes, a las cuales se refirió: la iglesia, los pósitos, los hospitales y teatros. Pero aún sorprende más por su elocuencia, que tratara de las cárceies después de referirse a los hospitales y antes de escribir acerca de los teatros, pues los tres tipos encierran un contenido científico en base a las leyes de la óptica, y están dentro de la necesidad referencial de la acústi-

Alberti, LeON BAPtista: "Los diez Libros de Architectura" de... Traduzidos de Latin en Romance. [Madrid] Alonso Gómez, año de 1582. B.R.A.S.F. B-1810

" AlBerti, LEON BATISTA: "L'Architettura" di... Tratotta in lingua Fiorentina de Cosimo Bartoli. Monte Regale, Lionardo Torrentino, [1565]. B.R.A.S.F.: B-83.

AlBerti, LEON BATISTA: "I dieci libri di Architettura" di ... Tradotti en italiano da Cosimo Bertoli... Nuova edicio ne. Foma, Govanni Zempel, [1784]. B.R.A.S.F.: B-1665.

"Balls, Benito: "Elementos de Matemáticas". Por .... Director de Matemáticas... Tom. Ix. Parte 1. Que trata de la Arquitectura civil. Segunda edición corregida por el autor. Madrid, en la Imprenta de la Viuda de D. Joaquín Ibarra, 1796. Se ocupó de las cárceles desde la pág. 866 a la 869. Véase el estudio de Pedro Navascués Palacio a la edición facsimil de Murcia, Colegio de Aparejadores y Arquitectos Técnicos de 1983. 
ca. Son edificios de concurrencia entre la arquitectura propiamente dicha y la física, la optica y hasta la acústica. Ello habla de la tendencia de los matemáticos de la Academia, del propio Bails y del polémico Antonio de Varas, de establecer nexos entre esa Bella Arte, que no tenía tan sólo que basarse en el dibujo, y otras disciplinas científicas.

Pero, si Bails dió unas opciones tipológicas claras a los edificios para la curación y la diversión del hombre, basadas respectivamente en los sistemas arquitectónicos franceses, en el prototipo hospitalario de Petit y en el modelo teatral de Patte, no proporcionó un modelo diáfano, sino más bien una aproximación al tema carcelario. Para ello acentuó su sitio dentro de la ciudad y la distribución de sus diferentes partes; pero siempre de un modo un tanto ambiguo, desdibujado.

Diferiendo de las concepciones clasicistas que establecian las cárceles en el interior de la ciudad, en las zonas más transitadas para evitar evasiones, prefirió con toda modernidad localizarla en su arrabal por motivos de ventilación, pues en la periferia urbana hay un aire más puro que en el centro, debido a la existencia de una mayor población. Pospuso, así, urbanisticamente las normas de seguridad, que hasta entonces habian prevalecido, a las de salubridad, y de aqui, quizá, su tratamiento en el libro, realizado inmediatamente después del edificio hospitalario.

Pero, además, en el tema de las cárceles parece tener un influjo preferentemente inglés, los auténticos especialistas en este prototipo, basado en estudios sobre la salubridad de Pringle, primer médico del rey de Inglaterra, y de Zimmermann, frente al predominio francés de sus otras tipologias y las referencias italianas realizadas, sobre todo, a través de Milizia. De ahi el interés del eclecticismo antológico de Bails, que muy posiblemente dió siempre al tema clásico sólo un matiz referencial, prefiriendo las soluciones coetáneas, las más novedosas y funcionales, al enfrentamiento directo con los tratados clasicistas, cuando estableció tipos de edificios. Todo ello, quizá, sea el segundo aspecto que le diferencia, en su calidad de matemático que se incurre ocasionalmente en la arquitectura, de la mayoría de los arquitectos de la Academia, anclados en una recuperación muchas veces casi exclusivista y sistemática del clasicismo a través de la tratadistica y de las ruinas tan en boga entonces. Con sus opciones de arquitectura moderna de base más científica que humanistica, es posible que estableciera una línea funcional, seguida poco después por algunos arquitectos, que tomaron al clasicismo como punto de partida referencial para conseguir una recreación, actualizándolo.

Bails manifestó una doble directriz en la arquitectura carcelaria: primero ventilación; pero también seguridad. Concedió tanta importancia a uno 
como otro factor, porque, siguiendo las ideas de la época, era un edificio realizado no para castigar, sino a fin de custodiar a los delincuentes.

También estableció la distribución de la cárcel en base a la idea médica de su necesaria ventilación. Frente a la angostosidad, hacinamiento y falta de higiene deseó que el presidio fuese amplio y bien distribuido. Organizó los cuerpos del edificio por medio de un primer patio con soportales. Distinguió entre la parte común y de gobierno, y la reclusión propiamente dicha. De esta forma dispuso en el piso bajo el despacho para el segundo alcaide, la sala de Tribunal, la escribanía, comedores, una capilla con sacristía, vivienda para el capellán, una enfermería y salas de locutorios. Las celdas las distribuyó en un segundo cuerpo del edificio; pero estableció una doble diferencia en ellas en función del tipo de delitos cometidos y también de la distinción social del delincuente. Los presos, que habian delinquido gravemente ocuparían celdas secretas. Los más distinguidos habitarian piezas particulares, mientras que el resto compartirian salas. En medio de ellas dispuso un sitio espacioso con árboles para la ventilación y la salud de los encarcelados.

Junto a la norma de salubridad estableció la imprescindible de solidez de la fábrica de la cárcel, cubierta con bóvedas y rodeada de fuertes muros, que servirían de recinto. Pero asimismo se mostró, ortodoxo con el clasicismo, partidario de que la arquitectura carcelaria fuera rústica y decorada de forma muy sencilla a base de cuerpos rectilíneos, dispuestos con euritmía en los lados opuestos.

En la Academia de San Fernando hubo una importante imagen carcelaria, modelo y cita romántica de clasicismo para todas las artes, aquí ineludible de reseñar, que de alguna forma debió incidir en la imaginación de sus profesores: las inevitables cárceles de Piranesi, incluidas en sus grabados de la "Opere varie di Architettura", que conoció tres tiradas entre 1745 y $1750^{19}$. En la biblioteca de tal centro se halla -estaba ya en el inventario de 1793 de Pascual y Colomer- uno de los ejemplares más importantes de esta obra de ese último año, en donde la arquitectura se hace pintura y hasta escultura por medio del grabado al aguafuerte y del buril a base de grandes contrastes de clarooscuro. Su incidencia en la práctica arquitectónica española de la llustración fue más referencial e imaginativa que pragmática al establer un estado mental clasicista con mucho de romanticismo y un deseo de revisión.

"PIRANESI, GIO. BATISTA, "Opere varie di architettura prospettive grotteschi antichita sul gusto degli Antichi romani. Inventate, ed incise da..., architetto veneziano. In Roma, 1750. 113 estampas, fol., $56 \mathrm{~cm}$.. Incluye las Carceri di invenzione. B.A.S.F.: A-1077. 


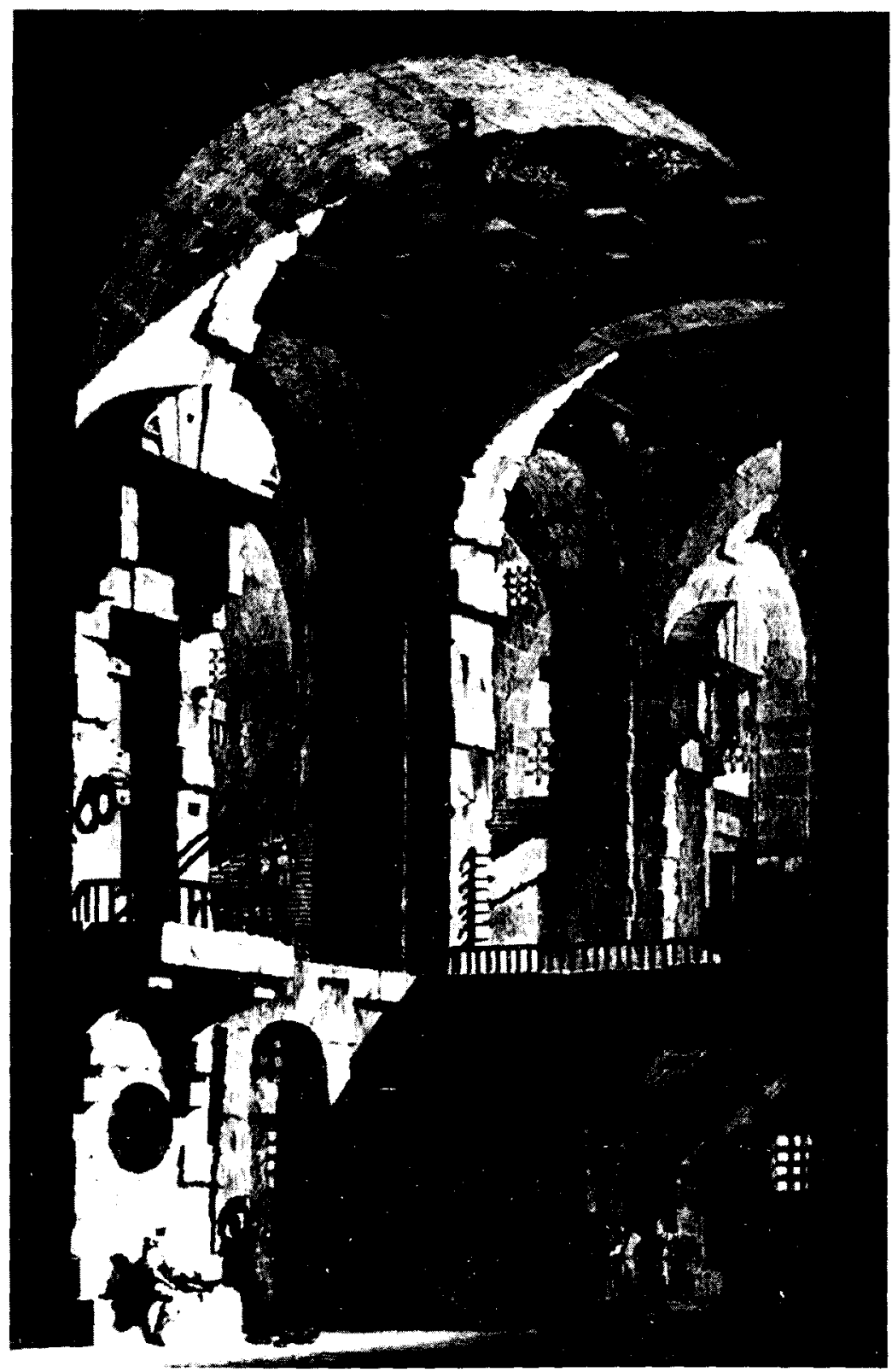

Lám. II. Giovanni Battista Piranesi: "Carcere oscura con Antenna pel suplizio dè malfatori». En el libro "Opere varie di Architettura prospettive grotteschi antichita sul gusti degli Antichi romani». Roma, 1750. 
Las láminas, grabadas por Piranesi en Roma hacia 1745 después de viajar a Venecia, son prisiones, espacios arquitectónicos tanto de tortura física como moral, que parecen ser cárceles más para auténticos colosos y hasta dioses, salidos de la mitología greco-romana, que para hombres. Sus arquitecturas de enormes proporciones, envueltas en una atmósfera dramáticamente romántica por violentos contrastes de luz y de sombras, reflejan una magnificencia extraordinaria. Edificios reelaborados a partir de citas clásicas muestran espléndidas bóvedas y arcos colosales sobre pilares enormes. Los amplios espacios interiores son escenarios de auténticas torturas, en cuyos muros se pueden contemplar ventanales enrejados, cadenas y máquinas, puentes y escaleras que conducen hacia no se sabe donde. Toda esta escenografía carcelaria tan teatral parece relacionar la vida tortuosa del penado, que sufre su crimen, con la liberación hipotética tras de la muerte.

Al mismo tiempo que en España se proyectaban numerosas cárceles siempre dentro de la tradición formal clásica y estando la mayoría de ellas incorporadas a los edificios de las Casas Consistoriales de las villas como un conjunto representativo, el inglés Jeremy Bentham (1748-1832) escribia un libro, el "Panóptico", que revolucionaría la tipología carcelaria decimonónica. Era un auténtico filósofo de la jurisprudencia, que desarrolló en sus escritos los conceptos del utilitarismo, del hedonismo social y también de la aritmética moral. Hizo éticamente coincidir el bien con el placer y el mal con el dolor al establecer una escala comparativa de los distintos placeres en función de su relación con la felicidad.

El libro de Bentham se publicó en 1791. Coincidió en el tiempo con el final del primer periodo de existencia de la Comisión de Arquitectura, delimitado por la vicesecretaría de José Moreno. Tuvo rápidamente una gran resonancia en Europa y repercutió en el diseño decimonónico de las prisiones. Basado en su peculiar visión filosófica del derecho, proporcionó un modelo para la tipología arquitectónica carcelaria muy congruente con su pensamiento. La planta es circular de seis pisos. Las celdas individuales se disponen a lo largo de su perímetro. En el centro colocó un puentetorre de vigilancia, desde la cual se divisa todo lo que ocurre en la cárcel.

Se pueden observar ciertos nexos bastante apreciables entre este modelo de prisión de Bentham con las leyes físicas de la óptica y hasta de la acústica. Es posible establecer alguna relación entre este ejemplo carcelario y la tipología teatral. El francés Patte y el italiano Milizia la estaban sometiendo a revisión pocos años antes de la publicación del libro de Bentham. Trataban de hallar un sistema arquitectónico, que permitiera un grado de visión y de audición mucho más perfecto. $Y$ entre otros aspectos, como, por ejemplo, el del uso de los materiales más adecuados, se basaban 
para conseguirlo en la búsqueda de la curvatura más útil para esta planta en función de esas coordenadas óptica y acústica. Se debatió sobre cuál de las dos curvas, la semicircular clásica y la elíptica, permitía más percepción al espectador. Bentham introducía ahora un modelo circular para la cárcel a fin de que los vigilantes observaran lo que ocurría en el interior de las celdas. Asi se estaba desarrollando a finales del siglo XVIII una auténtica arquitectura de la visión con mucho de visionaria por adelantarse al futuro, de la cual el tema del hospital también participaba de alguna manera, coincidiendo ambas tipologías en la necesidad higiénica de una ventilación imprescindible recomendada por la Medicina.

Bentham consideraba que mediante el empleo adecuado de la arquitectura era posible aumentar la seguridad en las cárceles, disminuyendo el gasto al mismo tiempo que se mejoraba la salubridad, la limpieza y el orden. Pero su propuesta tenía un componente ético, pues trataba de asegurar una buena conducta en los presos asi como su enmienda. Para ello promovió la idea de aislamiento y de control constante de los reclusos ${ }^{20}$.

\section{LAS CÁRCELES ESPAÑOLAS ENTRE 1777 Y 1808, Y LA COMISIÓN DE ARQUITECTURA DE LA ACADEMIA}

Durante las tres últimas décadas del siglo xvIII se construyeron estas obras públicas cívicas en muchas localidades españolas más o menos pequeñas, quizá como consecuencia de las mejoras experimentadas en los caminos del Reino. Obviamente las villas y las ciudades, que atravesaban tales carreteras, también debían cambiar su aspecto estético y poseer edificios pragmáticos. La cárcel, espacio físico para la detención, el castigo y, asimismo, ahora para la reeducación moral de los muchos bandoleros de los caminos y también de hospedaje de los copiosos mendigos, que iban y venian sin rumbo fijo por España, era un edificio en relación estrecha casi siempre con el Ayuntamiento, la casa de la autoridad local. Se puede considerar junto a la Iglesia Parroquial como una de las construcciones más representativas del lugar, levantándose muchas veces

Un libro espléndido en el que se establecen las bases ideológicas de las cárceles y de la ciencia penitenciaria española durante los siglos $x$ vili $y \times 1 x$ es el de Pedro Fraile, "Un espacio para castigar". La cárcel y la ciencia penitenciaria en España (siglos XVIII-XIX). Barcelona, Ediciones del Serbal, 1987. Se retiere en concreto a tres encierros durante la llustración: la cárcel de Sevilla, el penal de Ceuta y la cárcel de Corte de Madrid. Además dedica gran atención a Bentham. De gran interes también es "Arquitectura carcelaria en España" de Antonio Bonet Correa, en "Historia 16". (Extra VII). Octubre de 1980. 


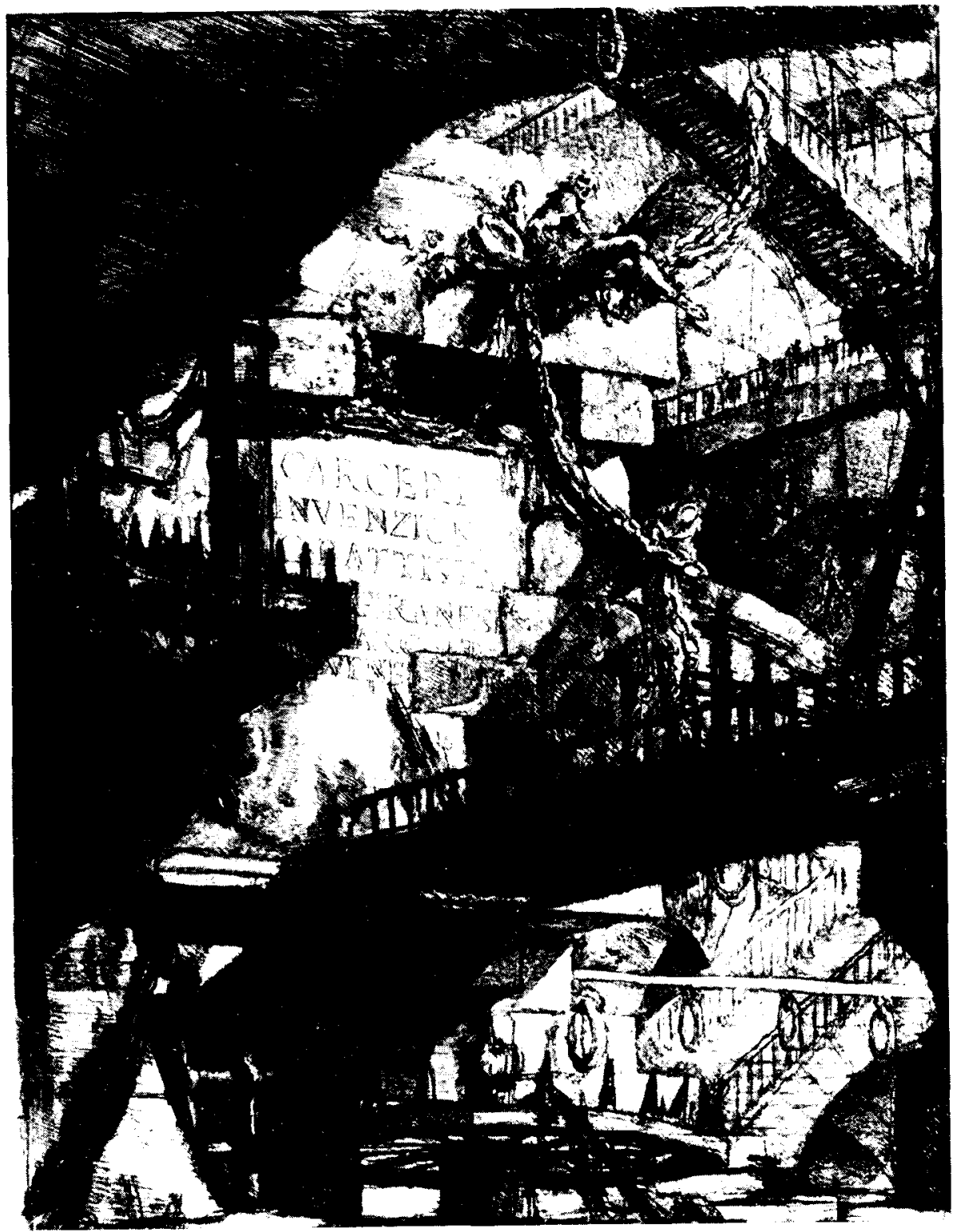

Lám. III. Piranesi: "Carceri invenzione». En "Opere varie». 
presidiendo la plaza mayor, que por su continua concurrencia se consideraba, así lo confirma la tratadística clasicista, como el lugar más seguro e idóneo para evitar las fugas.

Por todo ello, las cárceles de la llustración española, desde la de Burgos (1772-73) a la de Cádiz (1792-1836), dos modelos importantes, podrian clasificarse en aisladas o exentas, generalmente las prisiones reales y provinciales, encerradas entre muros, y anejas o muy próximas a las Casas Consistoriales. Estas eran sitio de retención, sobre todo, interina de acusados de muy diversas categorías, como criminales, bandoleros, mendigos..., que después del juicio solían pasar a ocupar las otras cárceles y las prisiones, en donde recibian sus castigos correspondientes. Aquellas otras se hallaban repletas, hacinadas, de delincuentes, que cumplían largas penas por delitos de muy distinta especie. Por esta causa exigian mayores normas de seguridad y capacidad, que las unidas a los Ayuntamientos de las villas españolas.

Pero, a pesar de esta dispariedad de funciones, siempre debian reunir, especialmente las primeras, unas ciertas condiciones, algunos de cuyos postulados se racionalizaron de una forma sistemática durante la llustración europea. Estas necesidades eran en primer lugar de seguridad y salubridad, que se obtenian mediante su edificación en sitio estratégico, capaz y urbanisticamente despejado, y el empleo de los elementos arquitectónicos precisos para lograr la necesaria ventilación con el fin de evitar las epidemias, por desgracia hasta entonces bastantes frecuentes, especialmente las pestes. La salubridad exigia que los presidios dispusieran de la luz y de la ventilación necesarias. También debian poseer la comodidad, aspecto que contrastaba arquitectónicamente al menos en apariencia con el de seguridad, aunque la mejor confianza fuera siempre la de un buen gobierno. La comodidad obligaba a poseer la capacidad imprescindible.

Al arquitecto correspondía, por lo tanto, delimitar la forma y la distribución de la cárcel. Pero ambos aspectos debian proyectarse también relacionándolos íntimamente con la filosofía jurídica con base moral sobre las penas de los delincuentes. El último tercio del siglo de la llustración fue un momento de revisión en Europa tanto de estos principios jurídicos y éticomorales del castigo como del espacio físico de la cárcel. La tipología arquitectónica penal dependía estrechamente de una filosofia y de una pedagogía moral carcelaria, que casi siempre la precede. En este sentido hay que citar aquí tanto a Burton como a Howard $y$, sobre todo, a Bentham. El pensamiento arquitectónico carcelario español ya del primer tercio del siglo Xix girará en torno a ellos. 
Las normas del derecho penal y, también, arquitectónicas de la tipología carcelaria a finales de la llustración se basaban en esos postulados de seguridad, capacidad, comodidad, higiene y reeducación moral. Pero para lograrlo sería imprescindible que el edificio procurase también una clasificación o separación departamental de los presos e inspección fácil, una continua ocupación en el trabajo e instrucción religiosa, la incomunicación de algunos de ellos y su estancia solitaria de noche. Estas eran las necesidades, que definian, al menos en un nivel teórico, la tipología carcelaria ya bien entrado el siglo xIx en España, como consecuencia del pensamiento precedente de la llustración.

No obstante, aunque en el transcurso de la segunda mitad del siglo XVIII se quisieron imponer estas condiciones para humanizar los lugares de encierro, la realidad de los presidios españoles era bien distinta y venía heredada en gran parte del periodo anterior. La teórica no siempre tenia una base empírica. Así, las referencias de la época sobre ellos nos hablan de pésimas condiciones de salubridad por la escasa ventilación interior y por el hacinamiento de los presos, que se alojaban en grandes salas todos revueltos, contagiándose tanto las enfermedades como las inadecuadas costumbres morales. La ausencia de vanos hacia el interior obscuro e insalubre para el cuerpo y el espíritu, predisponiendo toda esta atmósfera ambiental más a reincidir en el delito que a la regeneración. Sin embargo, hubo importantes intentos para mejorar la situación, tal y como se puede comprobar al analizar el libro de juntas de la Comisión de Arquitectura y varios legajos del Archivo de la Academia madrileña. Pero en España pesaba aún demasiado el sistema carcelario heredado del Antiguo Régimen, al que se superpusieron los dictados del clasicismo académico muchas veces más formales que estrictamente basados en los principios jurídicos y éticos.

\subsection{A modo de inventario de proyectos de cárceles censurados por la Comisión de Arquitectura}

Numerosus expedientes y diseños para la realización de Casas Consistoriales con cárceles incorporadas o adjuntas, y presidios exentos llegaron a las juntas ordinarias de la Academia desde 1777 y a su Comisión de Arquitectura a partir de 1786, para que se dictaminara sobre la calidad de los proyectos. Se realizaron al parecer muchas más en la zona central de la Península, en ambas Castillas, Extremadura y Andalucia, que en su periferia costera, especialmente en la mediterránea catalana y levantina. Aragón es la gran excepción en esta geografía carcelaria de la época, pues no se han localizado. Algunos de estos proyectos 


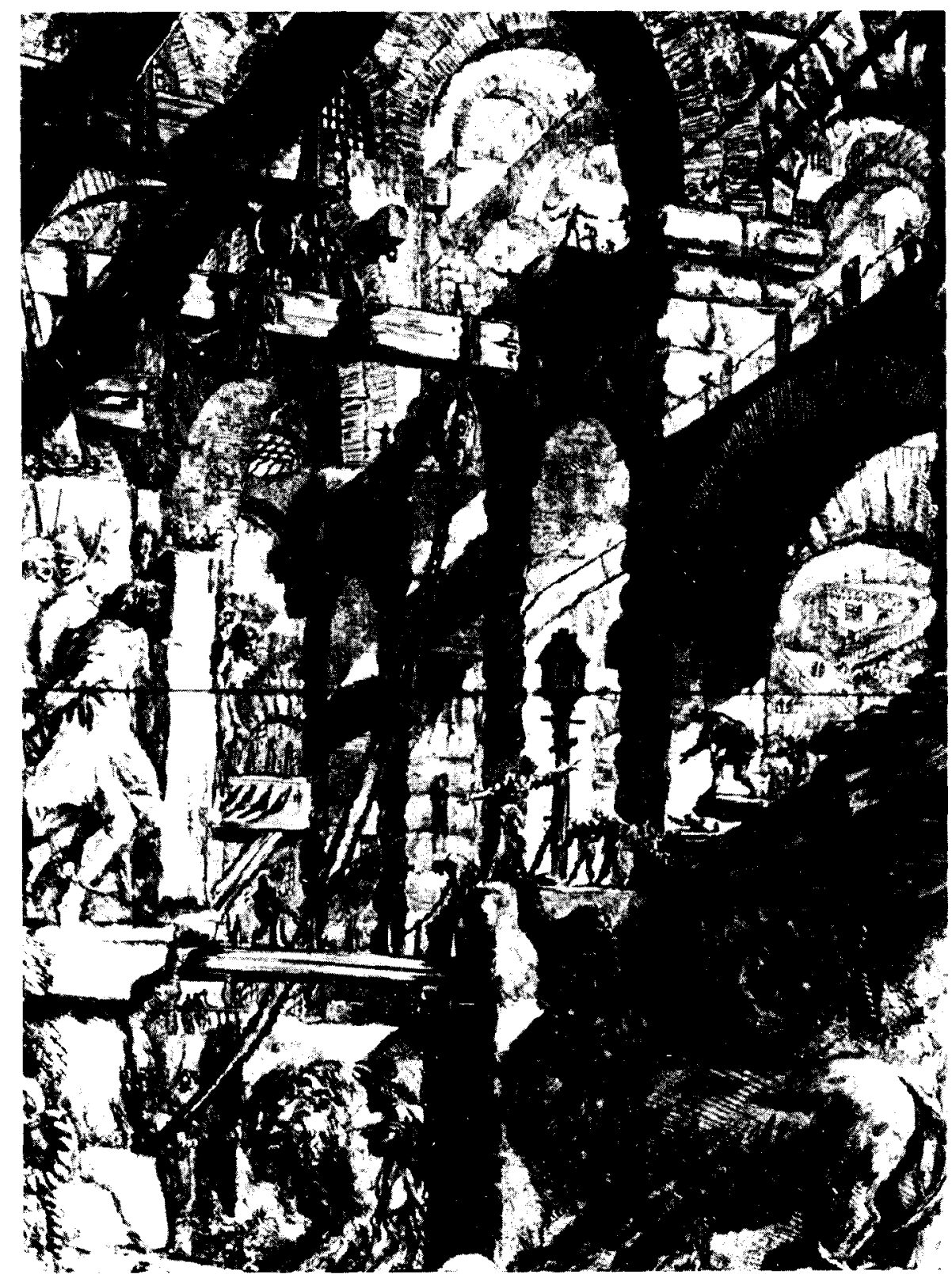

Lám. IV. Cárcel de Piranesi. Grabado al aguafuerte y buril. Ejemplar de la Biblioteca de la Real Academia de Bellas Artes de San Fernando. 
no se construyeron o se llevaron a término después, ya avanzado el siglo XIX, con nuevos dibujos, tal y como ocurrió, por ejemplo, con la cárcel de Orense. Predominan más los presidios en ayuntamientos que los exentos, que exigían otras condiciones arquitectónicas más precisas.

No escaparé aquí a la tentación erudita, pero necesaria debido a la falta de un inventario, de enunciar por regiones los proyectos de obras carcelarias, que llegaron a la Real Academia de San Fernando para su censura entre 1777 y 1808 por exigencia de las reales órdenes de Carlos III. Ello nos proporciona, además de una idea de su gran número, la visión panorámica de la arquitectura carcelaria y de ayuntamientos de la época, tan sólo superada cuantitativamente por la construcción de puentes, debido al importante nuevo trazado de las carreteras españolas llevado a cabo en este periodo ${ }^{21}$. Tan sólo me referiré más extensamente a algunas de ellas a modo de ejemplo debido a la falta de espacio en este artículo.

En la zona norte española no fueron tan numerosas como en el centro peninsular. Así, en Galicia: En La Coruña: casas consistoriales de Betanzos (1778) con trazas de Antonio Cándido García, pero con las fachadas de Ventura Rodríguez. Carceles públicas de Orense (1787-98) y de Pontevedra (1816).

Los proyectos de estas cárceles gallegas fueron realizados por los arquitectos Melchor Prado y Mariño (Pontevedra), Miguel Ferro Caaveiro, Juan López Freire, Francisco Martínez Vidal y Alejo Andrade Yáñez, quienes diseñaron consecutivamente dibujos para la de Orense, que es, junto con la de Zamora, una de las cárceles más documentadas del archivo de la Academia madrileña. Su realización se demoró a lo largo de mucho tiempo, pues en 1831 aún no se había construido.

El primer proyecto para la construcción de una cárcel pública en Orense, que sustituyera a la antigua, se aprobó en la junta de la Comisión de Arquitectura del 17 de marzo de 1787. En esta ocasión se habian presentado dos ideas alternativas: la de Juan López Freire, que se titulaba profesor de la ciudad de Santiago, expuesta en siete dibujos e informe facultativo, y la de Miguel Ferro, arquitecto de la misma localidad, que comprendía cuatro diseños. Se prefirió la de éste último, proponiéndosele también para dirigir la construcción de la fábrica, por la

2 La relación incluida en este articulo de cárceles exentas y en casas consistoriales se ha obtenido del A.A.S.F. con la consulta de los legajos siguientes: Arquitectura. Cárceles. 1782-1837: leg.: 30-1/2.- Casas consistoriales: legs.: 30/4-2 y 30-4 bis-2 .- Actas de la Comisión de Arquitectura: $139 / 3$ y $139 / 4$. 
regularidad e inteligencia, que denotaba tanto en la disposición como en la economía ${ }^{22}$.

Si el primer proyecto para la cárcel nueva de Orense lo diseñó Ferro, uno de los facultativos de confianza de la Academia en Galicia, otro incluyendo siete dibujos con dos planos para la construcción de una nueva cárcel en la villa de Pontevedra fue realizado por Melchor de Prado y Mariño ya en 1816, siendo aprobado en todas sus partes por su buena disposición ${ }^{23}$. Este arquitecto académico había tenido problemas con ese instituto con motivo de las obras realizadas por él en el interior de la catedral de Lugo.

Sin embargo, algunos años después, el 13 de junio de 1793, la Comisión tuvo que intervenir otra vez reafirmando su dictamen anterior para la cárcel de Orense. Las autoridades de esta ciudad remitieron de nuevo al Consejo y este organismo de gobierno a la Academia los proyectos de Freire y de Ferro, ya juzgados; pero, además, enviaron cuatro planos recientemente formados por el maestro arquitecto aprobado Francisco Martín Vidal para que se informase sobre las ventajas que ofrecian. La junta volvió a reconocer todo el expediente, mas se confirmó en su anterior dictamen favorable a Ferro porque "sobre ser más conforme a una fábrica destinada a cárcel, era su repartición interior más juiciosa y regular que la de los demás». La Comisión también contradijo la pretensión de la ciudad, que quería que se la permitiese confiar la ejecución material del edificio a un maestro cantero de su satisfacción por su menor costo. Corroborándose en su dictamen anterior se insistió en que el autor de la traza dirigiera la ejecución de la obra o en su defecto otro arquitecto aprobado ${ }^{24}$.

No obstante, el 27 de junio de 1798 Alejo Albo, en orden de poder de la ciudad de Orense, escribió una súplica para que el proyecto de Ferro Caaveyro, ya fallecido, fuera sustituido por otro nuevo ideado por Francisco Martínez Vidal, maestro arquitecto. La ciudad envió la nueva propuesta al Consejo, que remitió a su vez el expediente a la Academia, para que la Comisión decidiese. El secretario Isidoro Bosarte dirigió, después de pasar por la junta particular del 5 de agosto, la representación

\footnotetext{
2. Actas de la Junta de la Comisión de Arquitectura del 17 de marzo de 1787. A.A.S.F.: 129/3, fol. 52 rev.

¿.: Expediente de la cárcel de Pontevedra en A.A.S.F.: leg.: 30-1/2. El proyecto fue aprobado el 23 de marzo de 1816 .

${ }^{24}$ Actas de la junta de la Comisión de Arquitectura del 13 de junio de 1798. A.A.S.F.: $139 / 3$. fol. 300 rev. -301 anv.
} 


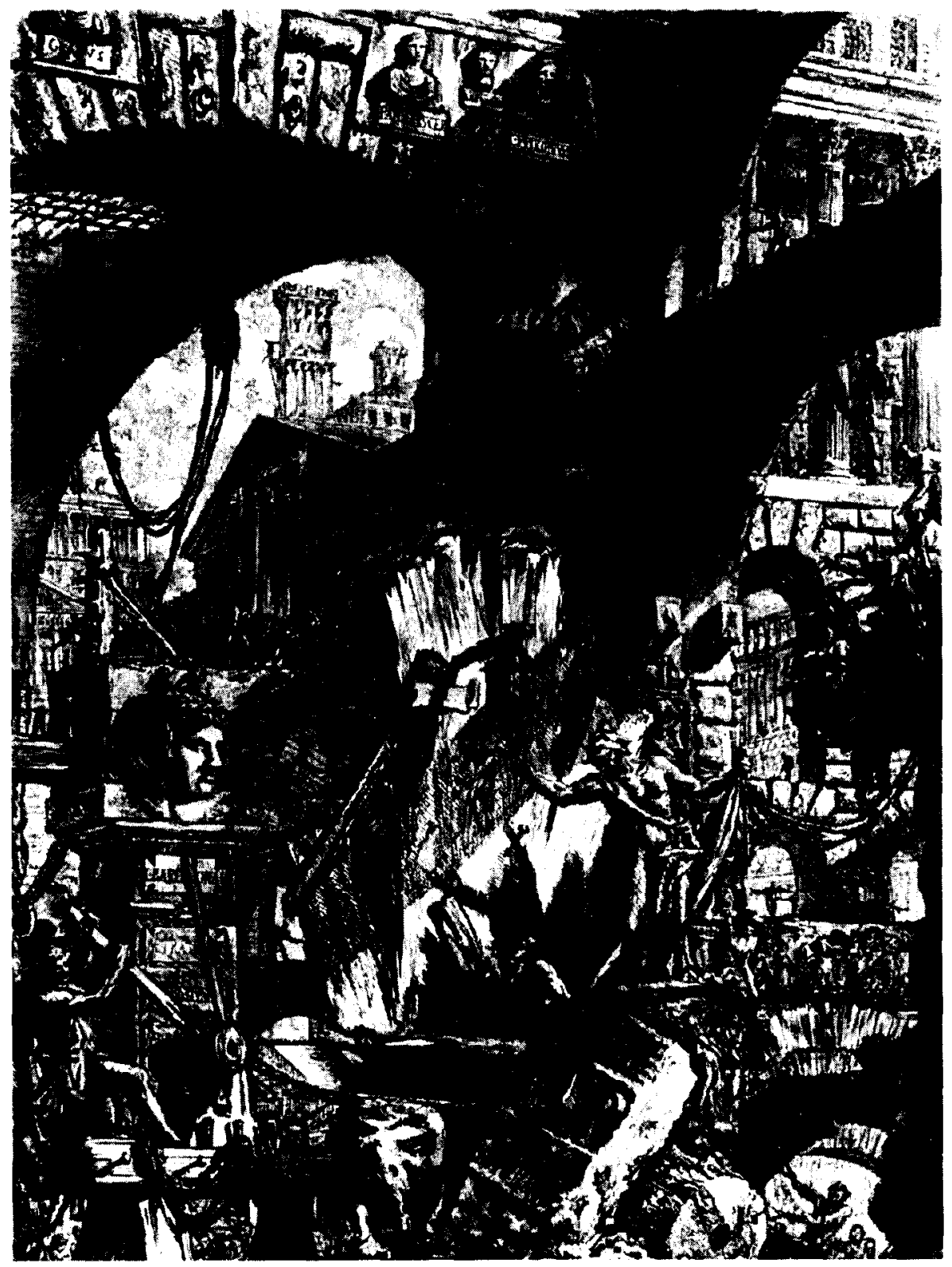

Lám. V. Cárcel de Piranesi. Las debió realizar en Roma hacia el año 1745-1750 después de regresar de su viaje a Venecia. 
de Albo a Luis Paret; que lo era de este servicio, junto con una carta explicativa, resumiéndose las pretensiones de la ciudad. Se aludía a varios motivos para preferir el nuevo proyecto al ideado por Ferro, que en resumen pueden agruparse en razones de seguridad, salubridad y económicas. Tales motivos estuvieron casi siempre presentes en todas las censuras de la Academia, siendo auténticos condicionantes de la tipología carcelaria.

Sin embargo, previamente se deseaba influir en el ánimo del instituto al hacer ver que, mientras Ferro era tan sólo maestro de obras, Martínez Vidal tenía el título de arquitecto por esa Real Academia de San Fernando. Aquel, por lo tanto no poseía las facultades debidas para encargarse de una obra de la primera consideración, tal y como era la cárcel de toda una provincia con un importante número de presos.

En primer lugar era necesario demoler la cárcel antigua para construirla de nuevo. Lo que obligaba a sacar los numerosos presos custodiados en ella. Además, el lugar en el que se erigía era insano, produciendo infecciones tan graves como la peste, que entonces se había declarado. La provincia renunciaba a ahorrarse los mil doblones, ahorro que, según la junta de la Comisión, produciría la ejecución del plano de Ferro, pues prefería su construcción en otro paraje más capaz, despejado y saludable, pues un arroyo pasaba por las inmediaciones.

Este recurso de la ciudad de Orense fue el único tema analizado en toda una junta, la del 3 de agosto de 1798, para cuyo estudio exclusivo los profesores de arquitectura de la Academia se habian reunido. La urgencia del caso lo exigía así, pues era necesario realizar dicha cárcel lo antes posible, «atendidos los perjuicios que se seguían a la salud del vecindario por la estrechez y situación de la fábrica antigua». Pero, además, la Academia debía contradecir heterodoxamente su dictamen anterior. El nuevo estudio se justificaba afirmando que el proyecto formado por Francisco Martinez Vidal era más a propósito respecto del nuevo sitio y otras circunstancias que el antiguo de Ferro ${ }^{25}$.

El proyecto de Martínez Vidal mereció la aprobación en sus líneas generales de los profesores de arquitectura de la Academia; pero en la junta ordinaria del 1 de septiembre se aceptó la propuesta de la Comisión de que el arquitecto se presentara a la mayor brevedad ante el director de arquitectura

26. Actas de la junta de la Comisión de Arquitectura del 3 de agosto de 1798. A.A.S.F.: 139/3, fol. 302 rev. -303 anv. 
Manuel Martín Rodríguez, para que reservadamente le comunicara varias correcciones necesarias, que debia ejecutar en los planos. Hecho lo cual, se aprobó definitivamente en la junta de Comisión del 31 de agosto de $1798^{26}$.

La cárcel provincial de Orense no se habia concluido aún en 1831 a pesar de las prisas de 1798. En este año se presentó a la Academia un diseño de fachada y presupuesto para su terminación, ideado por el académico de mérito Alejo Andrade Yañez. En el nuevo proyecto se suprimía el segundo cuerpo segun el diseño antiguo, porque no se consideraba necesario ni había fondos suficientes para construirlo. La Academia lo aprobó en todas sus partes el 16 de agosto de 1831, siendo Inclán Valdés secretario de la Comisión de Arquitectura.

En el Principado de Asturias: hospital, ayuntamiento y cárcel de Cangas de Tineo (1790). En Cantabria: casas consistoriales y otras obras de Santander (1787). En Euzkadi: En Vizcaya: cárceles de Guernica (1793) y Luno (1793). En Guipúzcoa: casa consistorial, cárcel, posada y escuela en Orendain (1787); ayuntamiento, cárcel y mesón de Salinas de Léniz (1789); casa consistorial con agregado de diferentes oficinas de Villafranca (1797); reedificación de la cárcel de San Sebastian (1803). En Alava: ayuntamiento de Vitoria (1793). Ya en La Rioja: cárcel pública de la villa de Cervera del Río Alhama (1786-87); casa consistorial y cárcel de Soto de Cameros (1787); casas consistoriales y cárcel de Nájera (1789).

En Castilla-León se censuraron en la Academia los presidios y las cárceles en las Casas Consistoriales siguientes: En León: ayuntamiento de Bembibre (1785). En Palencia: ayuntamiento, panera y cárcel de Manquillos (1792). En Burgos: casas consistoriales, cárcel pública y carnicería real de Nava de Roa (1786); ayuntamiento, cárcel y carnicería de Villodrigo (1787); ayuntamiento con varias oficinas públicas de Arcos (1792). En Zamora: casa consistorial de Toro (1778) por Ventura Rodríguez; ayuntamiento, cárcel y paneras de Castrillo de la Guareña (1787); casa capitular, cárcel, matadero, graneros y pontones de Roales (1787); cárcel de Zamora (1790-93); carcel de Castro Gonzalo (1791). En Valladolid fueron bastante numerosas: casas capitulares de San Cebrián de Mazote (1787): ayuntamiento con hospital, paneras, cárcel y escuela de Tamariz de Campos (1787); cárcel de Medina de Rioseco (1788); ayuntamiento, cárcel y carnicería de la villa de Rodilana (1787); ayuntamiento,

4. Actas de la junta de la Comisión de Arquitectura del 31 de agosto de 1798. A.A.S.F.: 139/3, fol. 303 anv. 


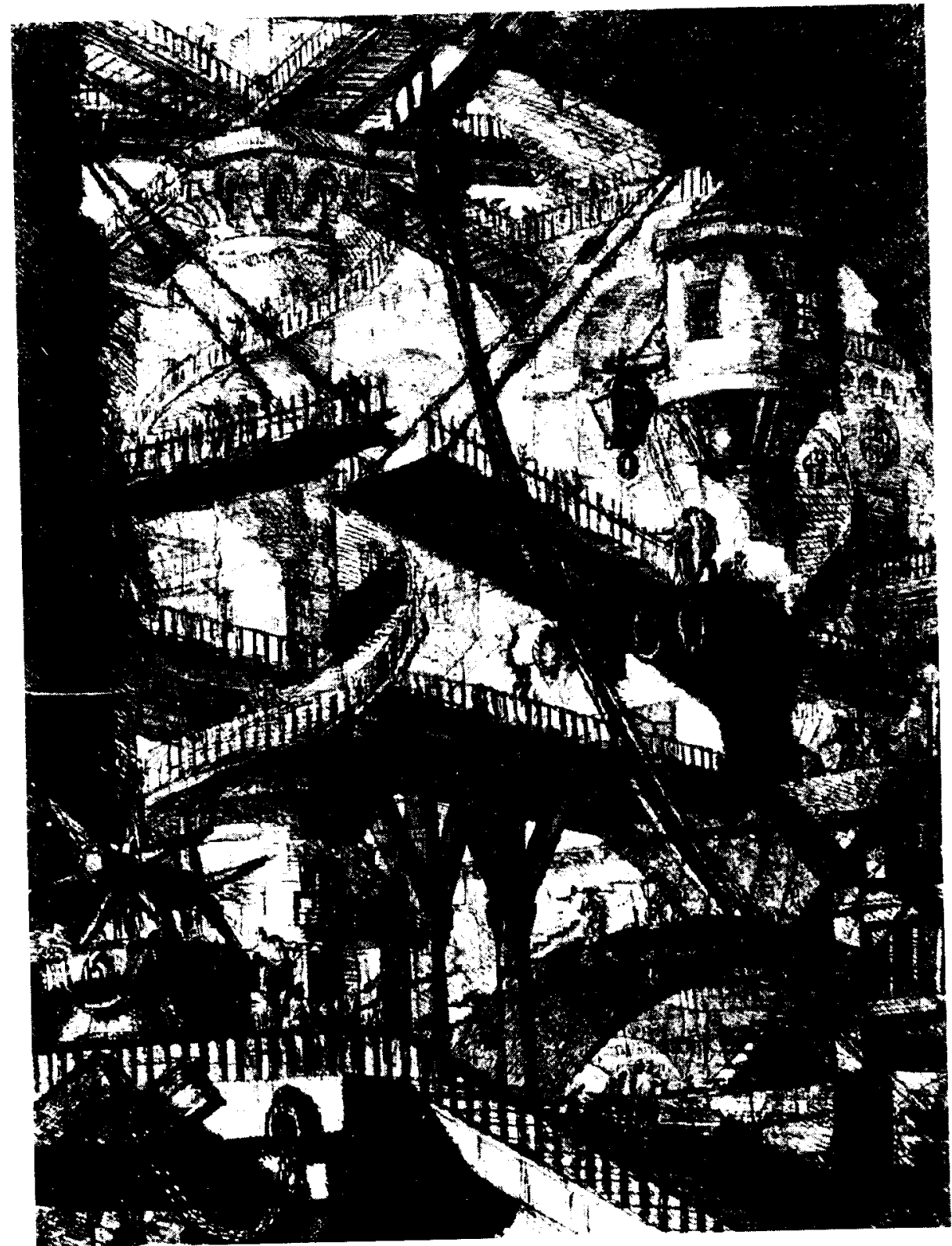

Lám. VI. Cárcel de Piranesi. Esta primera edición conoció tres tiradas entre 1745 y 1750. 
cárcel y mesón de Laguna (1787); casas consistorjales de Viana de Cega (1788); ayuntamiento de la Seca (1788); ayuntamiento y otras oficinas públicas de Castrodeza (1790). En Salamanca: carnicería y carcel de Arcediano (1786); casas consistoriales, panadería y cárcel del lugar de Macotera (1787); casas consistoriales, cárcel y capilla de Ciudad Rodrigo (1790); ayuntamiento con archivo y escuela de Villamayor (1791); cárcel de Aldea Dávila (1807). En Avila: ayuntamiento de Navaluenga (1780); casas consistoriales de Burgohondo (1787); ayuntamiento de Avila (1795).

La desaparecida cárcel real de Burgos, construida entre 1772 y 1773 , es uno de los ejemplos más elocuentes de la arquitectura carcelaria del período inmediatamente anterior a las censuradas por la Academia primero en sus juntas particulares desde 1777 y después en las de la Comisión de Arquitectura a partir de 1786. Francisco Alejo de Miranda, residente en esta ciudad entre 1772 y 1782. diseñó el proyecto, cuya construcción fue dirigida por Fernando González de Lara, el arquitecto de confianza de la Academia en tierras burgalesas. Era la época durante la cual la supervisión de los proyectos de obras públicas arquitectónicas corría a cargo de Ventura Rodríguez por disposición del Consejo de Castilla.

La cárcel real burgalesas, cuyo proyecto fue aprobado por Carlos III el 24 de noviembre de 1774 , disponiendo que su coste se repartiera entre los distintos pueblos del distrito, se realizó en la plaza del Mercado Mayor, a donde daba su fachada principal. Ocupó aproximadamente el solar del actual Palacio de la Diputación Provincial y fue derribada hacia 1860. Tal situación junto a una plaza céntrica de la urbe para impedir las fugas estaba en consonancia con la ubicación tradicional de las cárceles españolas de la época, siguiendo también los dictados de la tratadistica arquitectónica.

Este edificio tenia formalmente mucho de palacio tanto por su fachada principal, singular por su carácter representativo, como por la nobleza de los materiales empleados, la sillería. Su planta era rectangular con entresuelo y dos pisos, destacando el primero. Se pretendía dignificar con la fachada la plaza céntrica de la urbe por hallarse en ella el mercado. Ocho pilastras toscanas, que se almohadillaban en el piso inferior, recorrían los superiores, realzándose el cuerpo central rematado por un frontón triangular con puerta adintelada con otro frontoncillo partido de reminiscencia barroca ${ }^{27}$.

Sobre la cárcel real burgalesa: IGLESIAS RouCO, Lena Saladina: “Arquitectura y urbanismo de Burgos bajo el reformismo ilustrado (1747-1813)". Burgos, Caja de Ahorros Municipal, 1978, págs. 71-74. También de la misma autora: “Burgos en el siglo XIX. Arquitectura y urbanismo (1813-1900)". Valladolid, Universidad, 1979, págs. 130 y 141-142. 
Entre los años 1790 y 1799 la Comisión de Arquitectura tuvo que ocuparse en varias ocasiones del proyecto para la construcción de una nueva cárcel en Zamora, cuya principal problema era determinar el sitio más conveniente dentro de la ciudad. Se pueden señalar dos fases distintas en la intervención académica: la primera se ocupó de la realización del proyecto y comprendería los años 1790-1793, y durante la segunda etapa la junta tuvo que actuar en la desestimación de ciertas denuncias, que le habian llegado sobre la modificación por parte del arquitecto director de las obras del plan ideado por Manuel Machuca para adaptarse a la auténtica configuración del terreno.

En la junta del 23 de octubre de 1790 fueron examinadas tres opciones presentadas en dos diseños realizados por el profesor Pedro Castellot; pero los dibujos se reprobaron, pues parecieron de cierta entidad algunos defectos encontrados en la parte de la disposición y en la buena forma. Además, en el expediente habia informes muy diversos y discordes entre si sobre la elección del lugar, que su fábrica ocuparia. Como alternativa se proponía su construcción o en la plazuela de San Martín o en la Casa del Conde de Castroterreño. No obstante, varios dictámenes se oponian a su edificación en esa plazuela, entre ellos una representación de las Mionjas de San Bernabé, que se quejaban de los perjuicios y escándalos, que la erección de tal cárcel en las inmediaciones a las tapias de su huerta ocasionaría a las religiosas. Extrañaba a los profesores de la Comisión, que no se hubiera preguntado a Castellot su opinión sobre este asunto o que su idea se hubiera silenciado. Se acordó en esta reunión, que el profesor declarara con juramento acerca del sitio que a su juicio era más acomodado para la fábrica y, también, que se llamara de Salamanca a Juan de Sagarvinaga, para que asimismo dictaminase sobre el particular 0 , si este arquitecto despertase ciertos recelos de parcialidad por haber estado al principio relacionado con el asunto, la Academia designaria a otros facultativo “integro, hábil y práctico» de Zamora ${ }^{28}$.

Al año siguiente se recibió en este instituto un segundo proyecto de cárcel para esta ciudad, que incluía dos diseños y condiciones del académico Juan de Sagarvinaga y del profesor Pedro Castellot. Se había diseñado con la idea alternativa de que ocupase o una parte derribada del palacio del Conde de Alba de Listre o el sitio de los estudios en la plazuela de San Andrés. El proyecto no agradó rotundamente a los profesores

2* Actas de la Junta de la Comisión de Arquitectura del 23 de octubre de 1790. A.A.S.F. 139/3, fol. 149 anv. y rev. 


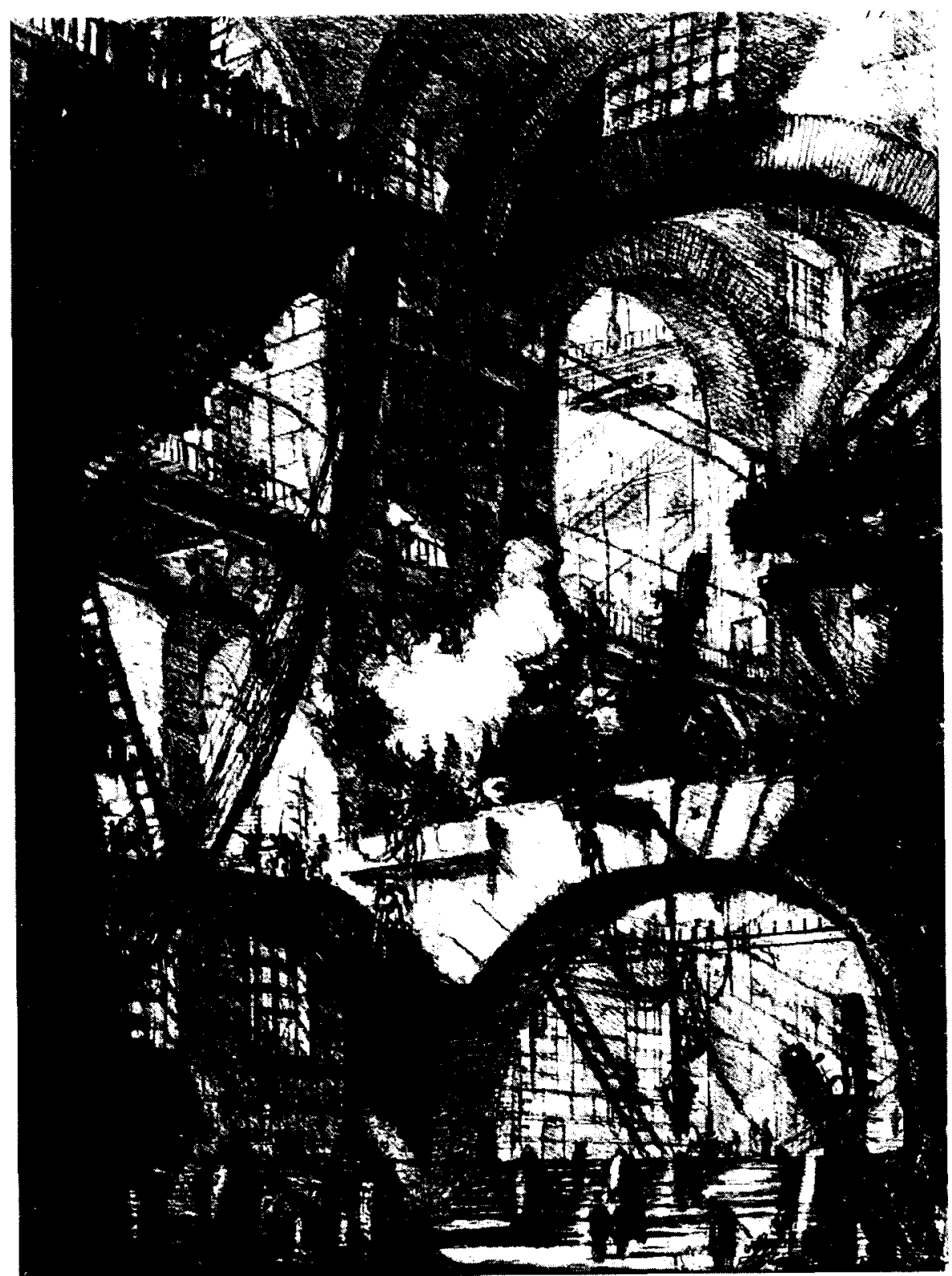

Lám. VII. Cárcel de Piranesi. Otras ediciones en 1761-1778, 1778-1799 y en Paris entre 1800 y 1809 . 
de la Comisión y en las actas de la junta del 19 de octubre de 1791, las últimas que José Moreno firmó como Vicesecretario unos días antes de su fallecimiento, se expuso con toda elocuencia: "Desde luego se tuvo por increible que Sagarvinaga (que tan acreditada tiene su pericia) hubiese intervenido en la formación de estos diseños que carecen de simetría, de distribución y de forma recomendable según su magnitud, destino y precio; siendo verosimil que Sagarvinaga sin haberlos hecho los haya firmado por indulgencia, o que muestre ya en esta obra la decadencia de su edad muy avanzada". Por tal motivo se acordó que la Junta de Policía de Zamora mandara hacer unos dibujos convenientes, como parte interesada en el decoro y beneficio público de esa ciudad, o, en su defecto se enviase un plan general del sitio destinado a cárcel, indicándose de una forma razonada las oficinas, habitaciones y otras comodidades que habria de contener para que un arquitecto de Madrid formara un proyecto arreglado ${ }^{29}$.

En efecto, Juan de Membiela, como Contador de Propios, remitió pocos meses después, el 12 de enero de 1792, todo el expediente a la Academia a traves de Manuel Alvarez ${ }^{30}$. Manuel de Lardizábal, Fiscal del Consejo y Cámara, hizo presente cuanto la Junta de Policía de Zamora había expuesto a petición de la Comisión de Arquitectura en su reunión del 19 de octubre de 1791. Se quería que a la vista de todo el expediente tal servicio se sirviera elegir y proponer el sitio o paraje más a propósito para la nueva cárcel. En él iban, tres planos instructivos del terreno, en el cual se podía construir, mostrándose la preferencia por ocupar la casa del Conde de Castroterreño. También se incluía un informe del ingeniero Beltrán de Beaumont. La junta eligió a Manuel Machuca para realizar el proyecto en su reunión del 27 de marzo de $1792{ }^{31}$ y en la del 22 de diciembre sus diseños en borrador fueron aprobados por considerarse la idea arreglada en todas sus partes ${ }^{32}$, aprobación que se confirmó en la del 8 de marzo de 1793 al presentarse por el Contador de Propios los cinco planos difinitivos y el informe que este Teniente Director realizó ${ }^{33}$.

En 1798 aún se estaba construyendo la cárcel de Zamora. En este año el profesor Manuel de Sipos remitió al contador ce Propios Juan Muñoz de

24. Actas de la Junta de Comisión de Arquitectura del 19 de octubre de 1791. A.A.S.F.: 139/3, fol. 174 rev.

A.A.S.F.: leg.: 30-1/2

: Actas. A.A.S.F.: 139/3, tol. 184 anv.

3) Ibidem, fol. 212 anv.

sa lbidem, fol. $217 \mathrm{rev}$ 
Valdivielso una declaración jurada y dos planos comparando la planta, que por diseños de Machuca se edificaba, con una nueva delineada por él y una regulación del costo necesario para acabarla. Quería demostrar que Castellot, director de la fábrica, había cometido varios defectos al alejarse de la idea inicial. El Consejo pedía a la Academia su dictamen y que determinara la responsabilidad, en que había incurrido, así como acerca de todas aquellas propuestas conducentes «al beneficio, perfección y menor costo de la obra». También solicitaba un informe sobre el mérito facultativo y el grado de pericia de Sipos, y si podía atenderse a su declaración y cálculo, o si seria más acertado que se practicase un reconocimiento de la obra realizado por un profesor de confianza, domiciliado en las inmediaciones de Zamora.

La Comisión contestó en su junta del 29 de noviembre de 1798 que no conocia a tal profesor por no tener acreditada su pericia en la Academia. Propuso indistintamente para realizar el reconocimiento o a Juan Marcelino de Sagarvinaga, residente en Salamanca, o a Francisco Alvarez de Benavides, quien vivía en Valladolid ${ }^{34}$. El primero de ellos realizó el informe, que se estudió en la junta del 27 de junio de 1799. Afirmaba que Sipos se había engañado. No había que atender a su reclamación ni a su avance de coste por ser excesivo. Castellot se había portado con el mayor celo; pero se vió obligado a realizar algunas innovaciones, porque desde el principio del proyecto se había incurrido en un error de demarcación del sitio para la cárcel, equivocación en la cual Manuel Machuca también cayó al delinear sus planos. En lo demás se estaba siguiendo sus diseños. Todo lo construido hasta la fecha tenía la solidez y la economía debida. También se aprobaba la cantidad que a su juicio faltaba para concluir la obra ${ }^{35}$.

En la actual Comunidad de Castilla la Mancha. En Guadalajara: ayuntamiento, archivo, carniceria y cárcel de Fuente Novilla (1779); ayuntamiento de Castilmimbre (1780); ayuntamiento, carnicería y matadero de Brihuega (1795). En Toledo: cárcel y carnicería de Huerta de Valdecarámbanos (1779); peso, cárcel y carniceria de Corral de Almaguer (1786-1792); reedificación de un lienzo de la plaza, repeso, carnicería y matadero de Yepes ( 1788 ); posada, escuelas, cárcel y pósito de Valmojado (1791); cárcel, cuarto del peso y sala capitular de la villa de Madridejos (1792). En Cuenca: cárcel y ayuntamiento de Hontanaya (1780); ayuntamiento, cárcel y otras oficinas de Valdecabras (1782); ayuntamiento y cárcel de

Ibídem, fol. 306 anv.-307 rev.

lbidem, fol. 311 rev. -312 anv. 
Sisante (1786); ayuntamiento de Salvacañete ( 1786 ); casas consistoriales de Villaescusa de Haro (1791); ayuntamiento y otras oficinas en Paracuellos (1793). En Ciudad Real: cárcel contigua al ayuntamiento de Herencia (1786); cárcel, sala de ayuntamiento y granero en San Carlos del Valle de Santa Elena (1787); casas consistoriales y cárcel de Ballesteros de Calatrava (1788); ayuntamiento y cárcel de Torre de Juan Abad (1789); ayuntamiento, cárcel, carnicería y mesón de Alhambra (1789); ayuntamiento, cárcel y fuente pública de Albaladejo (1790); casas consistoriales, cárcel y carnicería de Villahermosa (1792). En Albacete: ayuntamiento, archivo, cárcel y carnicería de Lezuza de la Mancha (1778-80); casas capitulares, cárcel, carnicería y lavadero de la villa de las Casas de Ves (1785).

En Extremadura: Cáceres: casas consistoriales y cárcel de Cilleros (1787); reparación de la cárcel y casas consistoriales de Plasencia (1787); ayuntamiento de Tornavacas (1789); nueva cárcel y casas consistoriales de Higuera (1792); casas consistoriales, archivo y cárcel de Rivera (Oveja?) (1793). En Badajoz: cárcel de Llerena (1778); casas consistoriales y cárcel de Cabeza del Buey (1782); casas consistoriales, cárcel y torre para reloj de Usagre (1785-1792); casas consistoriales y cárcel de Villagarcía de la Torre (1786); ayuntamiento y cárcel de Torre de Almendral (1788); cárcel de la villa de Medina de las Torres (1792); casas consistoriales, archivo y cárcel de Ribera del Fresno.

En Andalucía. En Huelva: casas consistoriales, cárcel y pescadería de Trigueros (1778); casas consistoriales y cárcel de Cartaya (1786); casas consistoriales de Gibraleón (1788); cárcel de Zalamea la Real (1790). En Sevilla: Casa capitular y cárcel de Alcalá de Guadaira (1778); casas capitulares, cárcel y pósito de Guillena (1779); casa consistorial con cárcel de Tocina (1779); casas consistoriales y cárcel de Guadalcanal (1786); casas capitulares, cárcel y escribanía de Castillo de las Guardas (1786-87); cárcel de Ecija (1798). En Córdoba: pósito, cárcel, carnicería y peso público de Villaharta de San Juan (1781); cárcel pública y ayuntamiento de Pozoblanco en los Pedroches (1786-87); cárcel de Aguilar de la Frontera (1797). En Jaén: ayuntamiento de Andújar (1787); casas consistoriales, cárcel, casa mirador y cárcel de mujeres de Villacarrillo (1790); cárcel de Alcalá la Real (1791). En Cádiz: casas consistoriales y demás oficinas de Puerto Real (1783): casas capitulares, archivo y cárcel de Jimena de la Frontera (1786); cárcel pública y carnicería de San Roque (1786); casas capitulares y cárcel pública de Ubrique (1786); cárcel de Cádiz (1792). En Granada: cárcel de Santa Fe (1790); cárcel real de Baza (1790-94); casas capitulares, cárcel, mesón tienda en Güejar de la Sierra (1791). En Málaga: casas consistoriales, cárcel y carnicería de Cortes de la Frontera 
(1778). En Almería: ayuntamiento y cárcel de Lauxar (1786); casas consistoriales, cárcel y mesón de Vera (1778); casas capitulares y cárcel de Roquetas (1786-1787); casas consistoriales, cárcel, carnicería y escuela de Berja (1787).

Otro edificio carcelario exento de gran interés es el de Cádiz, cuyo proyecto, diseñado por Torcuato José Benjumeda, discípulo de Torcuato Cayón, fue censurado en la junta del 13 de septiembre de 1792. Los seis dibujos realizados por este arquitecto, quien en 1816 diseñó el ayuntamiento de esta ciudad, con sus correspondientes informes y regulación económica se aprobaron. Pero la Comisión hizo una serie de advertencias a su proyecto para que las tuviera en consideración a la hora de construir la cárcel: que «suprimiese Benjumeda el primer plinto de la fachada, formando en su lugar un zócalo sin resaltos a la total altura de las gradas, y que sobre las pilastras de los ángulos del pabellón acomodase dos atributos, para que quedase aquella parte debidamente exornada" ${ }^{36}$

Sin embargo, la cárcel gaditana, iniciada en 1794 en un paraje junto a la muralla, no se concluyó hasta 1836 por el arquitecto Juan Daura, aunque su actuación está aún por determinar con total exactitud. El edificio, cuya fachada principal con el cuerpo central en avance es de sillares de piedra y mármol, se alza en dos pisos. Tiene planta rectangular con patio central principal y otros dos laterales, en torno a los cuales se distribuyen las diferentes dependencias.

Tampoco fueron muy numerosas las cárceles realizadas durante esta época en la zona mediterránea no andaluza: En Cataluña: En Lérida: casas consistoriales, cárcel y almusi de Balaguer (1787). En el país valenciano: En Valencia: casas consistoriales y cárcel de Gandía (1778); cárcel de Museros (1789). En Alicante: cárcel real de Villena (1786-87). En Murcia: casas consistoriales y mesón de Totana (1782).

En Madrid se realizó la reparación de las casas consistoriales y otras oficinas de Fuenlabrada (1789); ayuntamiento, cárcel y oficinas públicas de Velilla de San Antonio (1789); casas consistoriales de Alcalá de Henares (1791). Pero también se incorporó la casa oratorio del Salvador con la fábrica de la cárcel de Corte, tema muy controvertido por la actuación desleal de Mateo Guill primero con Juan de Villanueva y después con Pedro Arnal entre 1787 y 1789.

sii Ibidem, fol, 203 anv. Tambièn leg.: 30-1/2. 
Asi, los penales y las nuevas casas consistoriales y sus cárceles anejas de detención, desornamentadas por exigencias del clasicismo pero también por razones económicas, fructificaron a lo largo y a lo ancho de la geografía española entre 1777 y 1808. Sin embargo, en ocasiones se desconoce si tales ayuntamientos, cuya construcción solicitaban las localidades a la Comisión de Arquitectura a través del Consejo de Castilla por medio del contador de propios, disponían asimismo de cárceles en su interior, aunque quizá haya que pensarlo de esta forma por ser lo más común.

Después de la guerra de la Independencia, entre 1814 y 1830 , se realizaron algunas pocas cárceles de nueva planta en España, cuyos proyectos pasaron la censura de la Comisión de Arquitectura ${ }^{37}$. Hay expedientes de las de Astorga (1815) con diseños de Fernando Sánchez Pertejo, Pontevedra (1816) de Melchor Prado y Mariño, y Navalcarnero (1828) de Francisco Lino Fernández. En este último se decidió dos años después rehabilitar la antigua cárcel debido a los altos costos del proyecto inicial. El arquitecto leonés Sanchez Pertejo también vió aprobado en diciembre de 1828 sus planos para una cárcel en Bembibre. Otros diseños se reprobaron como los de Noya (1827) y Antequera (1829) por resultar incorrectos en su decoro, sin apropiada distribución y falta de ventilacion.

No obstante, la mayoría de las censuras aprobadas se correspondían con remodelaciones de antiguos edificios. No estaban los tiempos para realizar grandes gastos en la construcción de este tipo de edificios. Unas veces las fortalezas se convertían en presidios. De esta forma los diseños de Francisco Muñiz Lorenzana para la reparación, aumento y transformación en cárcel pública del Castillo de la ciudad de Oviedo se aprobaron el 19 de junio de 1817. La idea de 1829 de formar una cárcel pública en el arruinado castillo de Ronda se desaprobó. En ocasiones se trataba de adaptar un convento a presidio, tal y como ocurrió con la antigua iglesia de San Martín de Lérida según proyecto de Antonio Celles de 1818.

Pero la mayoría de las ocasiones se trataba de mejorar las cárceles existentes para ganar en higiene y seguridad. Asi ocurrió con la de Lorca, que se amplió con una nueva construccion siguiendo los planos de Antonio Prat. Algo similar sucedió con la real de Valladolid, que fue arreglada con el fin de conseguir más seguridad y ventilación de acuerdo con los proyectos realizados por Pedro Alvarez de Benavides y Pedro García

Los expedientes de las cárceles españolas censuradas en A.A.S.F.: legs.: 30-1/2 (cárceles. $1782-1837$ ); $30-2 / 2$ (cárceles, $1842-1853$ ) y $30-3 / 2$ (cárceles, $1853-1861$ ). 
González de 1826. También se aprobó la idea de Atilano Sanz para arreglo y nueva forma de la de Jaca de 1828.

\subsection{La censura académica de las cárceles}

Todos estos pueblos, villas y ciudades, y otras localidades cuyos expedientes también se enviaron a la Academia durante los años siguientes, tuvieron entonces sus proyectos para que se construyeran tales edificios en casas consistoriales y de forma exenta. La mayoría de ellos serian realizados por arquitectos académicos, después de reprobarse los diseñados por alarifes, maestros de obras y hasta albañiles y carpinteros locales pertenecientes a los Gremios por la Comisión de Arquitectura en sus juntas. En realidad, los proyectos y las realizaciones de tales edificios, junto a otros como puentes, dieron bastante trabajo a los arquitectos de la Academia, y fueron repartidos, tal y como era habitual, en función de las zonas geográficas de residencia de los distintos profesores.

Así pues, la inmensa mayoría de los diseños de cárceles realizados por los maestros gremiales fueron reprobados sistemáticamente por este instituto de las Bellas Artes. Había un doble motivo en tales rechazos: los constructores locales carecían de una formacion teórica de la Arquitectura y eran simples practicones. Por estas razones sus proyectos resultarian académicamente incorrectos. Solian desconocer los fundamentos del lenguaje arquitectónico basado en el dibujo y aún más los científicos proporcionados por el estudio de las matemáticas y de la física. Asimismo, seguían empleando, y aún abusando, la tendencia ornamental barroca excesiva por tradición, porque en su uso se habían formado. Estaban distantes de las formas clásicas entonces tan en boga, el nuevo lenguaje artístico internacional de la llustración, que los Borbones deseaban imponer en España para sacarla de su aislamiento.

No hacía falta negarles las aprobaciones de sus proyectos carcelarios y de casas consistoriales dando extensas explicaciones, porque ni se habian formado ni examinado en la Academia para conseguir el título y con él la legalidad vigente en el ejercicio de tal profesión. Sus proyectos eran suficientemente elocuentes por la falta de la imprescindible calidad arquitectónica y dibujística para ser rechazados con cierta facilidad y sin requerir minuciosos razonamientos por escrito.

Sin embargo, hubo una evolución en los informes de rechazo remitidos por el secretario de la Academia en forma de oficios al Consejo. Los motivos de las reprobaciones de los diseños para cárceles se indicaban mucho 
más extensamente en la década comprendida entre los años 1777, fecha de las reales cartas circulares, y 1786, que después de crearse la Comisión de Arquitectura. Ya se habían dado muchas razones al Consejo antes de fundarse este servicio para reincidir en ellas, repitiéndolas. Por ello desde entonces se emplearian fórmulas estereotipadas y burocráticas, sencillas pero elocuentes, que lo mismo valían para reprobar un proyecto de cárcel que cualquiera otra obra pública de alguna consideración.

Las respuestas más expresivas de la Academia se debieron a Antonio Ponz en aquel primer periodo. No podía ser de otra forma, dada la singular personalidad de este pintor y literato, su formación en el clasicismo más estricto, que conoció en Roma, y su crítica sistemática al barroco. Sus oficios académicos, en los que las formulas burocráticas se entremezclan con sus conocimientos estéticos, se hallan estrechamente relacionados con sus comentarios reprobadores de muchos edificios de esta tendencia artística, publicados en su “Viaje de España», y a veces resultan hasta más elocuentes aún. Siguen las directrices de las representaciones de la Academia al rey de 1769 y 1777 y de las reales cartas circulares de este año. Tal vez haya que relacionarlas con él de algún modo.

Una de las fórmulas de reprobación más repetida es la «falta de gusto e inteligencia del arte" ${ }^{38}$. La palabra "gusto» está siempre en relación con el paradigmático clasicismo vitruviano, mientras que la de «inteligencia» parece vincularse con la posesión de conocimientos teóricos, expresos en sus tratados. También solía aludirse a que los ornatos, una de las grandes obsesiones de la Academia, eran "ridículos y contrarios a la buena arquitectura", proporcionando "deformidad" y «extravagancia», aspectos todos ellos manifiestos en la representación de 1777 y las reales cartas circulares de noviembre de ese mismo año. Se insistía en algunas de las respuestas de censura de cárceles en que la buena construcción no consistía tan sólo en la «maniobra, solidez, mezcla y elección de los buenos materiales", conocimientos propios de un práctico albañil, sino en "las buenas y arregladas formas exteriores del edificio". Además, łales formas debian guardiar concordancia con el interior de la obra, resultando del todo "armonia, decoro y unidad". Pero también se encontraban aquí -y ello es bien importante de reseñar - las razones estéticas con las eco-

\footnotetext{
it Un ejemplo de estas fórmulas y de la elocuencia manifiesta entre 1777-1786, se halla en la censura de la casa capitular y cárcel de Alcalá de Guadaira (Sevilla). El oficio de contestación de Ponz, cuyo borrador fechado el 27 de junio de 1778 se halla en A.A.S.F.: leg.: 30-4/2, es muy expresivo.
} 
nómicas; se pensaba que el exceso de adornos ridículos encarecía la obra, produciendo dispendios, y contribuía también a malforma el gusto público.

Según pasaba el tiempo, después de remitirse estos expresivos dictámenes con bastante de discurso pedagógico -quizá ya sabidos de memorieta por los escribanos receptores de la Contaduría de Propios- las reprobaciones se justificaban simplemente con el uso de fórmulas casi siempre reiteradas con machaconería una y otra vez. De esta manera, por ejemplo, debido a la «mala forma» o «sin arreglo ni conocimiento de la buena arquitectura».

Pero a veces se explicaban más las causas del rechazo de los diseños. Asi, en la cárcel real de Baza (Granada) el proyecto de Santiago Ferro de 1790 fue reprobado porque "es un edificio vasto en que la buena distribución y las comodidades no corresponden a su coste" ${ }^{39}$. Clasicismo y economía se encontraban en los juicios de los arquitectos de la Comisión a la hora de valorar los planes. El afán estético clásico no estaba reñido con la aplicación de los costos adecuados, sino que parecía uno de sus condicionantes o derivó en ello.

Por lo tanto, la Academia deseaba sencillez y el menor gasto posible a la hora de construir estos edificios carcelarios y edilicios; pero también quería el empleo de una decoración que les diera un carácter más robusto y propio de su destino. Por esta razón la junta de la Comisión de Arquitectura recomendó, aún aprobando el proyecto de Francisco Quintillán y Lois, uno de sus arquitectos de confianza en Andalucía, para las casas consistoriales y cárcel de Laujar en Granada "la supresión de frontispicios de la fachada principal, dejando las cornisa corrida o con unos modillones, si se desea; que a las ventanas sobre el balcón largo se las echaran unas jambas sencillas, que sobre la del medio se colocara un escudo que podría ser algo más chico y que los ángulos de la fachada posterior se hicieran de piedra labrada para mayor firmeza» ${ }^{40}$. Tales consejos, tan extensos, no los daban a los maestros gremiales para que corrigieran sus diseños.

A.A.S.F.: leg:: 30-1/2. - Actas de las juntas de la Comision de Arquitectura del 14 de mayo de 1790 y, sobre todo, del 12 de marzo de 1794. A.A.S.F.: 139/3, fols. 141 rev. - 142 anv. y 244 anv. y rev.

40) Borrador del oficio de José MoREno del 1 de diciembre de 1786, A.A.S.F.: leg.: 30-4/2. También en las actas de la junta de la Comisión del 30 de noviembre de ese año, 139/3, fol. 46 rev. 